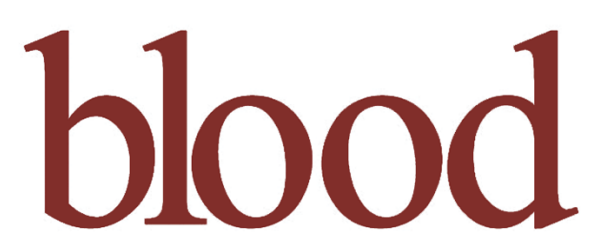

2007 110: 4526-4534

Prepublished online Sep 13, 2007;

doi:10.1182/blood-2007-01-067801

\title{
I branching formation in erythroid differentiation is regulated by transcription factor C/EBP\{alpha\}
}

Yuh-Ching Twu, Chie-Pein Chen, Chuang-Yi Hsieh, Cheng-Hwai Tzeng, Chien-Feng Sun, Shih-Hsin Wang, Mau-Sun Chang and Lung-Chih Yu

Updated information and services can be found at:

http://bloodjournal.hematologylibrary.org/cgi/content/full/110/13/4526

Articles on similar topics may be found in the following Blood collections:

Transfusion Medicine (187 articles)

Gene Expression (1086 articles)

Information about reproducing this article in parts or in its entirety may be found online at:

http://bloodjournal.hematologylibrary.org/misc/rights.dt|\#repub_requests

Information about ordering reprints may be found online at:

http://bloodjournal.hematologylibrary.org/misc/rights.dtl\#reprints

Information about subscriptions and ASH membership may be found online at:

http://bloodjournal.hematologylibrary.org/subscriptions/index.dtl

Blood (print ISSN 0006-4971, online ISSN 1528-0020), is published semimonthly by the American Society of Hematology, 1900 M St, NW, Suite 200, Washington DC 20036.

Copyright 2007 by The American Society of Hematology; all rights reserved.

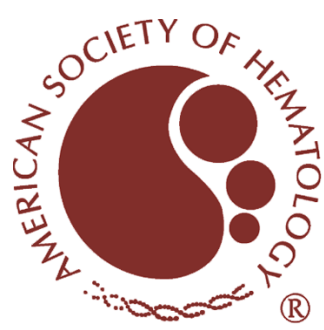




\title{
I branching formation in erythroid differentiation is regulated by transcription factor $\mathrm{C} / \mathrm{EBP} \alpha$
}

\author{
Yuh-Ching Twu, ${ }^{1}$ Chie-Pein Chen, ${ }^{2,3}$ Chuang-Yi Hsieh, ${ }^{1}$ Cheng-Hwai Tzeng, ${ }^{4,5}$ Chien-Feng Sun,, 67 Shih-Hsin Wang, ${ }^{8}$ \\ Mau-Sun Chang, ${ }^{3}$ and Lung-Chih Yu, \\ ${ }^{1}$ Institute of Biochemical Sciences, National Taiwan University, Taipei; ${ }^{2}$ Division of High Risk Pregnancy, Department of Obstetrics and Gynecology, Mackay \\ Memorial Hospital, Taipei; ${ }^{3}$ Department of Medical Research, Mackay Memorial Hospital, Taipei; ${ }^{4}$ Section of Transfusion Medicine, Department of Medicine, \\ Taipei Veterans General Hospital, Taipei; ${ }^{5}$ College of Medicine, National Yang-Ming University, Taipei; ${ }^{6}$ Department of Clinical Pathology, Linkou Medical Center, \\ Chang Gung Memorial Hospital, Taoyuan; ' ${ }^{7}$ Department of Pathology, School of Medicine, Chang Gung University, Taoyuan; and ${ }^{8}$ Institute of Biological \\ Chemistry, Academia Sinica, Taipei, Taiwan
}

The histo-blood group $\mathrm{i}$ and I antigens have been characterized as straight and branched repeats of $\mathrm{N}$-acetyllactosamine, respectively, and the conversion of the straight-chain $i$ to the branched-chain I structure on red cells is regulated to occur after birth. It has been demonstrated that the human I locus expresses 3 IGnT transcripts, IGnTA, IGnTB, and IGnTC, and that the last of these is responsible for the I branching formation on red cells. In the present investigation, the
K-562 cell line was used as a model to show that the i-to-I transition in erythroid differentiation is determined by the transcription factor CCAAT/enhancer binding protein $\alpha(C / E B P \alpha)$, which enhances transcription of the IGnTC gene, consequently leading to formation of the I antigen. Further investigation suggested that C/EBP $\alpha$ IGnTC-activation activity is modulated at a posttranslational level, and that the phosphorylation status of C/EBP $\alpha$ may have a crucial effect. Results from studies using adult and cord erythropoietic cells agreed with those derived using the K-562 cell model, with lentiviral expression of $\mathrm{C} / \mathrm{EBP} \alpha$ in $\mathrm{CD}_{3}{ }^{+}$hemopoietic cells demonstrating the determining role of $\mathrm{C} / \mathrm{EBP} \alpha$ in the induction of the IGnTC gene as well as in I antigen expression. (Blood. 2007;110:4526-4534)

() 2007 by The American Society of Hematology

\section{Introduction}

The blood group i and I antigens have been characterized as straight and branched repeats of the $N$-acetyllactosamine (LacNAc) structures, Gal $\beta 1-4 G l c N A c \beta 1-3 G a l \beta 1-4 G l c N A c-R$ and Gal $\beta 1-$ 4GlcNAc $\beta 1-3($ Gal $\beta 1-4 G l c N A c \beta 1-6) G a l \beta 1-4 G l c N A c-R$, respectively, carried on glycolipids and glycoproteins. ${ }^{1-5}$ First identified on human red cells, ${ }^{6-10}$ their presence was later also observed on the surface of most human cells and on soluble glycoproteins in various body fluids..$^{5,11-13}$ The LacNAc repeats are synthesized by the sequential action of $\beta-1,3-N$-acetylglucosaminyltransferase and $\beta$-1,4-galactosyltransferase. Conversion of the straight-chain i into a branched I-active structure requires the activity of the I $\beta-1,6-N$ acetylglucosaminyltransferase (I $\beta 6$ GlcNAcT). ${ }^{2,14,15}$

It has been demonstrated that the relationship between the expressions of the $\mathrm{i}$ and I antigen is reciprocal, and that the expression of I antigen on red cells is developmentally regulated. Adult human red cells fully express I antigens and contain only a few i antigens, while fetal and neonatal red cells predominately express the latter. After birth, the quantity of I antigen gradually increases as the level of $i$ antigen falls, until the normal Ii status of adult red cells is reached after about 18 months of life. ${ }^{10,16}$ On the other hand, it has been shown that the failure of conversion of $i$ to I is associated with several hematologic disorders, including thalassaemia, hypoplastic anemia, and acute leukemia. ${ }^{17}$ Thus, the transition between straight and branched poly-LacNAc chains may play a significant role in erythrocyte differentiation. One of the

Submitted January 11, 2007; accepted August 23, 2007. Prepublished online as Blood First Edition paper, September 13, 2007; DOI 10.1182/blood-200701-067801.

The online version of this article contains a data supplement. recognized findings with respect to the function of the straight poly-LacNAc structure on fetal and neonatal red cells is its protection against severe hemolytic disorder resulting from $\mathrm{ABO}$ incompatible pregnancy. ${ }^{18,19}$

Formation of the I branching structure on cell surfaces is determined by an uncommon molecular genetic architecture. The cDNA encoding the I $\beta 6 \mathrm{GlcNAcT}$ was first identified by Bierhuizen et al in $1993 .{ }^{20}$ The gene is designated IGnT (approved as GCNT2 by the Human Genome Organisation [HUGO] Gene Nomenclature Committee). In 2003, Yu et al and Inaba et al further elaborated the complexity of the human $I$ locus, demonstrating that it expresses 3 different transcript forms. ${ }^{21,22}$ These 3 transcripts, designated $I G n T A, I G n T B$, and $I G n T C,{ }^{21}$ have different exon 1 , but identical exon 2 and exon 3, regions. The 3 IGnT cDNAs do not have a common $5^{\prime}$ region, indicating that their transcriptions may be determined by different DNA regulatory regions. Indeed, the 3 transcripts display differential expression patterns in different human tissues. ${ }^{21,22}$ This observation suggests that the I antigens in the various cells are synthesized by different $I G n T$ forms whose transcriptions are apparently regulated by specific regulatory mechanisms.

In a previous investigation of samples from $\mathrm{i}$ adults, whose red cells (like fetal and cord analogs) are rich in the $\mathrm{i}$ antigen but contain little I, we demonstrated that IGnTC is the gene responsible for the expression of the blood group I antigen on red cells. ${ }^{21,23}$ This

The publication costs of this article were defrayed in part by page charge payment. Therefore, and solely to indicate this fact, this article is hereby marked "advertisement" in accordance with 18 USC section 1734.

C 2007 by The American Society of Hematology 
conclusion is further supported by the fact that IGnTC is the only 1 of the $3 I G n T$ transcripts that is expressed in reticulocytes, the red cell precursors. ${ }^{21}$ The aim of the present investigation was to elucidate the molecular mechanism responsible for the expression of I branching structure on red cells after birth. It was demonstrated that the i-to-I transition during erythroid differentiation is determined by the transcription factor CCAAT/enhancer binding protein $\alpha(\mathrm{C} / \mathrm{EBP} \alpha)$.

\section{Materials and methods}

Our program was approved by the Institutional Review Board at Mackay Memorial Hospital, Taipei, Taiwan. Informed consent was obtained in accordance with the Declaration of Helsinki.

\section{Erythroid differentiation of K-562 cells}

Human leukemia cell line K-562 (American Type Culture Collection, Manassas, VA) was grown in 90\% RPMI 1640 medium supplemented with $10 \%$ fetal bovine serum, penicillin $(50 \mathrm{U} / \mathrm{mL})$, and streptomycin $(50 \mu \mathrm{g} / \mathrm{mL})$. To induce erythroid differentiation, K-562 cells $\left(5 \times 10^{5} / \mathrm{mL}\right)$ were cultured in medium added with $1 \mathrm{mM}$ of sodium butyrate (Sigma, St Louis, $\mathrm{MO})$ for 2 days.

\section{Flow cytometry analysis}

To detect the cell-surface I antigen, the cells were incubated with human monoclonal anti-I antibody (mAb OSK14; a generous gift from Dr Yoshihiko Tani, Osaka Red Cross Blood Center, Japan) at $4^{\circ} \mathrm{C}$ for 2 hours after blocking with $5 \%$ bovine serum albumin. The bound monoclonal antibodies (mAbs) were detected by incubation with fluorescein isothiocyanate (FITC)-conjugated goat anti-human IgM (Serotec, Raleigh, NC), and the cells were subjected to flow cytometry (Epics XL; Beckman Coulter, Fullerton, CA).

\section{Quantification of IGnT and C/EBP $\alpha$ transcripts}

Preparation of cellular total RNAs and synthesis of cDNAs were performed as described previously. ${ }^{24}$ The forward IAF16, IBF18, and ICF20 primers (primer sequences are found in Document S1, available on the Blood website; see the Supplemental Materials link at the top of the online article) were used to amplify IGnTA, IGnTB, and IGnTC cDNAs, respectively, by polymerase chain reaction (PCR). The reverse primer used, IRs, was common for the $3 I G n T$ cDNAs. PCR for the $\beta$-actin cDNA was performed using the ACTF and ACTR primers. The cDNA sample and 2 pmole of each forward and reverse primer were added to $20 \mu \mathrm{L}$ of the SYBR Green Master Mix (Applied Biosystems, Foster City, CA). Real-time PCR detection (GenAmp 7300 Sequence Detection System; Applied Biosystems) was used for quantification of the transcripts. Serial dilutions of the pGEM-T vector (Promega, Madison, WI) containing IGnTA, IGnTB, IGnTC, or $\beta$-actin cDNAs were used to generate standard curves for each respective transcript.

The $C / E B P \alpha$ transcript in the cDNA sample was quantified using the TaqMan gene expression assay kit for $C / E B P \alpha$ (Applied Biosystems). Serial dilution of the pGEM-T vector containing $C / E B P \alpha$ cDNA was used to generate a standard curve.

\section{Reporter assay}

The DNA fragments encompassing the $-3359-$ to $+62-$ bp regions of the IGnTC gene (translation initiation codon as nucleotides +1 to +3 ) were PCR-amplified using the primers IC5'Fe and IC60R. Genomic DNA from K-562 cells served as the template. The amplified fragment was inserted into the KpnI and XhoI sites of the pGL3-basic vector (Promega), which contains the firefly luciferase reporter gene, yielding the $-3359 /+62$-bp reporter construct. The $S t u \mathrm{I}, E c o \mathrm{RV}$, and NdeI restriction sites, locating at the $-1524,-538$, and -318 positions, respectively, were used to digest the $-3359 /+62$-bp construct and shorten the encompassed IGnTC 5' region and, thus, built the $-1524 /+62-,-538 /+62-$, and $-318 /+62-$ bp constructs, respectively. The $-253 /+62$-bp and $-77 /+62$-bp segments were PCR-amplified using the reverse primer IC60R and forward primers of IC5' -253 and ICF2, respectively, and were then inserted into the XhoI site of the pGL3-basic vector, yielding the $-253 /+62$ - and $-77 /+62$-bp constructs. The -322 to $-251-b p$ region was PCR-amplified using the primers IC5'F-322 and IC5'R-251 and inserted into the SmaI site of the $-77 /+62$-bp construct, yielding the $-322 /-251 \&-77 /+62$-bp construct, which had the -322 to $-251-$ bp region inserted immediately upstream of the -77 to $+62-$ bp region.

Transfection of K-562 cells was performed as described previously. ${ }^{24}$ The cells were subsequently cultured in medium with or without sodium butyrate for 2 days before being harvested to analyze luciferase activity using the Bright-Glo Luciferase Assay System (Promega).

\section{Expression of Oct-2, Sp1, and C/EBP $\alpha$ transcription factors}

The full coding cDNAs for the Oct-2, Sp1, and C/EBP $\alpha$ factors were obtained by PCR using the primer pairs OCTF13K/OCTR14, SPF5/SPR6, and CEBPAF9/CEBPAR10, respectively, with the cDNA sample from the K-562 cells serving as the template. Each of the amplified cDNAs was cloned into the pcDNA3.1(-) mammalian expression vector (Invitrogen, Carlsbad, CA). At 72 hours after transfection of the K-562 cells, the transfected cells were enriched under the selection of antibiotic G418 $(1 \mu \mathrm{g} / \mathrm{mL})$ for 72 hours before harvesting.

\section{Nuclear protein extraction, immunoprecipitation, and Western blotting}

For nuclear and cytoplasmic protein extractions, the described protocols ${ }^{25}$ were followed with minor modifications. Protein concentrations were determined using the Protein Assay kit (Bio-Rad, Hercules, CA).

A total of $20 \mu \mathrm{g}$ of cytoplasmic and nuclear proteins were separated using $10 \%$ polyacrylamide gel electrophoresis and transferred to Immobilon-P membrane (Millipore, Billerica, MA). After blocking with 5\% bovine serum albumin, the blots were detected with anti-C/EBP $\alpha$ antibody (Santa Cruz Biotechnology, Santa Cruz, CA). The bound antibody was detected with horseradish peroxidase-conjugated secondary antibodies (Leinco Technologies, St Louis, MO), and the signals developed using Western Lighting Chemiluminescence Reagent Plus (PerkinElmer, Waltham, MA). After stripping, the membrane was blotted successively with anti- $\alpha$ tubulin (Abcam, Cambridge, United Kingdom) and anti-histone H1 (Stressgen, Victoria, BC) antibodies.

For analysis of the phosphorylation status of $\mathrm{C} / \mathrm{EBP} \alpha$, nuclear protein $(20 \mu \mathrm{g})$ was immunoprecipitated with anti-C/EBP $\alpha$ antibody $(1 \mu \mathrm{g})$ in a final volume of $500 \mu \mathrm{L}$ at $4{ }^{\circ} \mathrm{C}$ for 16 hours, and the antibody-bound proteins were then precipitated using protein A-sepharose CL-4B gel (Amersham, Piscataway, NJ). The bound proteins were separated using $10 \%$ polyacrylamide gel electrophoresis and transferred to Immobilon-P membrane. The blots were detected with anti-phosphoSer/Thr/Tyr, antiphosphoSer (Abcam), anti-phosphoTyr, and anti-phosphoThr (Santa Cruz Biotechnology) antibodies. The signals were developed as described. Each blot was then stripped and detected with anti-C/EBP $\alpha$ antibody.

\section{ChIP analysis}

Chromatin immunoprecipitation (ChIP) analysis was performed using the ChIP assay kit (Upstate, Charlottesville, VA). The described protocols ${ }^{25}$ were followed with minor modifications. Briefly, the cells were incubated in $1 \%$ formaldehyde for 10 minutes at room temperature to cross-link the transcription factors with chromatin DNA. The cross-linking reaction was quenched by addition of glycine ( $125 \mathrm{mM}$, final concentration). Cells were then lysed with ChIP lysis buffer. ${ }^{25}$ Chromatins in the lysates were sheared by sonication, and bound with anti-Oct-2, anti-Sp1, or anti-C/EBP $\alpha$ antibodies (Santa Cruz Biotechnology) at $4^{\circ} \mathrm{C}$ for 2 hours. The antibodybound chromatin DNAs were precipitated by protein A-agarose gel. After elution, the chromatin DNAs were relieved from the cross-linked proteins by heating at $65^{\circ} \mathrm{C}$ overnight, and precipitated in $70 \%$ ethanol. One-thirtieth of the immunoprecipitated DNAs or input DNA controls served as 
templates in the PCR amplification for the IGnTC -322 to +62-bp region using IC5'F-322 and IC60R primers. The products were analyzed using $2.0 \%$ agarose gel electrophoresis.

\section{Isolation of $\mathrm{CD} 34^{+}$and $\mathrm{CD} 71^{+}$cells and E culture}

Adult $\mathrm{CD} 34^{+}$and $\mathrm{CD} 71^{+}$progenitor cells were isolated from granulocytecolony stimulating factor (G-CSF)-mobilized peripheral blood stem cells and general peripheral blood cells, respectively. Neonatal $\mathrm{CD}_{3} 4^{+}$and $\mathrm{CD} 71^{+}$cells were isolated from umbilical cord blood cells. Mononuclear cells were first isolated from the blood samples by Ficoll density gradient using Ficoll-Plaque Plus (Amersham). $\mathrm{CD}^{+} 4^{+}$and $\mathrm{CD} 71^{+}$cells were purified using the Dynal CD34 Progenitor Cell Selection System (Invitrogen) and CD71 MicroBeads kit (Miltenyi Biotech, Bergisch Gladbach, Germany), respectively, following the manufacturers' protocols.

For erythropoietic $(\mathrm{E})$ culture, the $\mathrm{CD} 34^{+}$cells $\left(1.5 \times 10^{5} / \mathrm{mL}\right)$ were cultured in StemSPAN SFEM medium (StemCell Technologies, Vancouver, BC) supplemented with stem cell factor $(50 \mathrm{ng} / \mathrm{mL}$; StemCell Technologies) and erythropoietin (3 U/mL; Janssen-Cilag, Titusville, NJ) for 7 days.

\section{Lentiviral expression of C/EBP $\alpha$}

The packaging vector pCMVdeltaR8.91 and the vesicular stomatitis virus $G$ protein (VSV-G) envelope glycoprotein-expressing vector pMD.G were provided by the National RNAi Core Facility (Academia Sinica, Taipei, Taiwan). The full coding cDNA of $C / E B P \alpha$, obtained as described, was cloned into the pLenti6/V5-D-TOPO vector (Invitrogen), constructing the gene transfer vector pLenti6-C/EBP $\alpha$. HEK 293T cells (American Type Culture Collection), cultured in Dulbecco modified Eagle medium (DMEM) in 6-well plates $\left(10^{5}\right.$ cells/well), were transfected with the pLenti6-C/EBP $\alpha$ or mock pLenti6 vectors $(0.5 \mu \mathrm{g})$ together with pCMVdeltaR8.91 $(0.5 \mu \mathrm{g})$ and pMD.G $(0.1 \mu \mathrm{g})$ using Lipofectamine Transfection Reagent (Invitrogen). The medium was collected 48 hours after transfection, and the viron suspensions were concentrated through ultracentrifugation. The CD34 ${ }^{+}$ cells, cultured in StemSPAN SFEM medium in 24 -well plates $\left(3 \times 10^{5}\right.$ cells/well), were transduced with the produced viron in medium with added polybrene $(8 \mu \mathrm{g} / \mathrm{mL})$. The cells were transferred to 6-well plates 16 hours after transduction, and were cultured for 72 hours before harvest.

\section{Results}

Induction of I antigen and IGnTC gene expression in K-562 erythroid differentiation

It has been shown that K-562 cells differentiate into erythrocyte lineage when treated with histone deacetylase inhibitors such as sodium butyrate. ${ }^{26-29}$ Further, it has been demonstrated that the treatment of sodium butyrate elicits i-to-I antigen conversion in K-562 cells. ${ }^{30}$ As shown in Figure 1A, the original K-562 cells weakly express I antigen. This agrees with previous observation that $2 \%$ to $5 \%$ of $\mathrm{K}-562$ cells are I-antigen positive. ${ }^{30}$ When K-562 cells were cultured in medium supplemented with sodium butyrate for 2 days, the expression of I antigen is markedly induced. Benzidine staining was used to demonstrate the cells that express hemoglobin. ${ }^{31}$ The original K-562 cells were virtually devoid of benzidine-positive particles; after sodium butyrate treatment for 2 days, however, around $40 \%$ of the cells were positive with benzidine staining (data not shown), indicating induction of hemoglobin expression and erythropoietic differentiation in the K-562 cells.

To manifest which of the IGnT forms is responsible for the I antigen formation in butyrate-treated K-562 cells, expressions of the IGnTA, IGnTB, and IGnTC transcripts were quantitatively analyzed. The expression of the IGnTC transcript was shown to markedly increase, whereas $I G n T A$ and $I G n T B$ were not altered significantly, in butyrate-treated K-562 cells (Figure 1B), suggest-
A
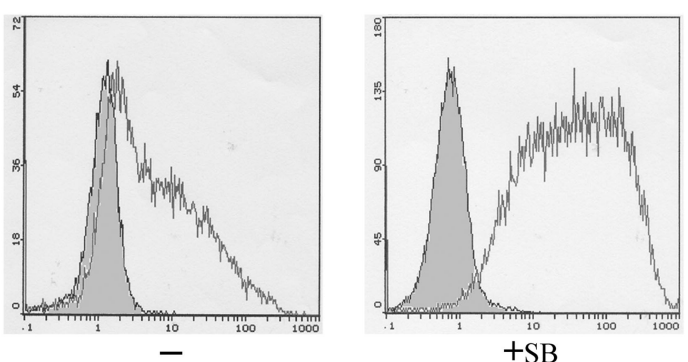

B

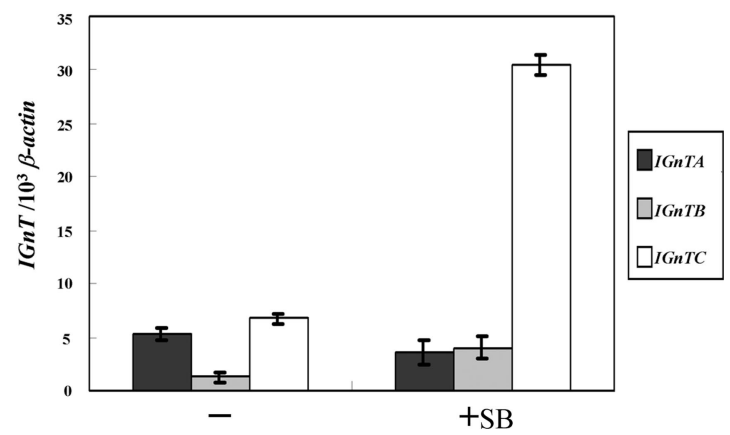

Figure 1. Expression of I antigen and IGnT genes in erythroid differentiation of K-562 cells. (A) Flow cytometry analysis for I antigen expression. K-562 cells were cultured in medium supplemented with $1 \mathrm{mM}$ of sodium butyrate for 2 days to induce erythroid differentiation. Expressions of the cell-surface I antigens on the K-562 cells with or without sodium butyrate treatment (indicated as + SB and - , respectively) were analyzed using flow cytometry and detected with monoclonal anti-I antibody (mAb OSK14; $1: 5$ dilution), with the bound mAb on the cell surfaces revealed by FITC-conjugated goat anti-human IgM (1:200 dilution). The open and shaded areas represent results obtained from cells incubated with anti-I mAb and FITC-conjugated secondary antibody, and with FITC-conjugated secondary antibody only, respectively. (B) Expression profiles for the IGnT transcripts. Real-time PCR was used to quantify the IGnTA, IGnTB, IGnTC, and $\beta$-actin transcripts in the cDNA samples. The quantities of the IGnT transcripts were normalized to that of $\beta$-actin transcript in each sample. Data were obtained from 3 detections; standard deviations are shown.

ing that the I antigen elevation in the erythroid differentiation of $\mathrm{K}-562$ cells resulted from the activation of IGnTC gene expression. This accords with our previous demonstration that IGnTC is the gene responsible for the I antigen formation in red cells. ${ }^{21}$

These results strongly suggest the feasibility of using this K-562 erythroid differentiation model for investigation of the molecular mechanism for I antigen formation in red cells.

\section{Identification of the cis DNA element regulating the transcription of the IGnTC gene}

A reporter assay was used to identify the cis-acting DNA element responsible for the regulation of IGnTC gene expression in K-562 erythroid differentiation. When the introduced IGnTC $5^{\prime}$ regions were shortened stepwise from nucleotide -3359 to -318 , the transcriptional activities enhanced by sodium butyrate treatment gradually increased (Figure 2A). However, the transcriptional activity of the $-253 /+62-b p$ construct was drastically reduced to a level similar to that of the pGL3-basic plasmid. This result suggests that a cis-acting DNA element responsible for the butyrate-induced activation of the IGnTC gene is located in the -318 to $-253-$ bp region. The $-322-251 \&-77 /+62-b p$ construct, which had the -322 to $-251-b p$ segment introduced upstream to the -77 to +62-bp region, exhibited strong transcriptional activities, especially when the transfected cells were treated with sodium butyrate, further supporting this suggestion. 
Figure 2. Identification of the cis-acting DNA region regulating IGnTC gene transcription. (A) Comparison of transcriptional activities of the IGnTC gene $5^{\prime}$ regions. Different $5^{\prime}$ segments of the IGnTC gene were introduced upstream of the luciferase reporter gene of the pGL3-basic vector. The $-322 /$ $-251 \&-77 /+62-$ bp reporter vector had the -322 to $-251-b p$ region inserted immediately upstream of the -77 to $+62-b p$ region. K-562 cells were split into 6 -well culture plates at a density of $2 \times 10^{5}$ cells $/ \mathrm{mL}$, and transfected with $1.0 \mu \mathrm{g}$ of the constructed and mock pGL3-basic reporter plasmids. The transcriptional activities of the constructed reporter plasmids in the transfected K-562 cells, with or without sodium butyrate treatment, are schematically represented by $\square$ and tively. The results are presented as averages of luciferase activities from 3 repetitions; standard deviations are shown. (B) Nucleotide sequence of the -318 through -253 region of the IGnTC gene. The putative binding motifs for the Oct-2, Sp1, and $\mathrm{C} / \mathrm{EBP} \alpha$ transcription factors are underlined.
A

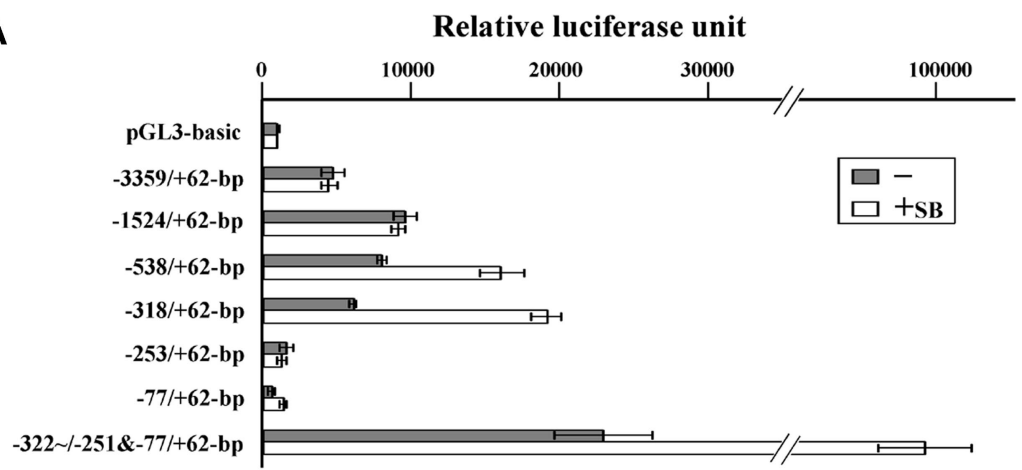

B
The -318 to $-253-$ bp nucleotide sequence was analyzed using the Transcription Element Search System utility from the Computational Biology and Informatics Laboratory at the University of Pennsylvania (http://www.cbil.upenn.edu/cgi-bin/tess/tess), ${ }^{32}$ and the putative binding motifs for the transcription factors of Oct-2, $\mathrm{Sp} 1$, and $\mathrm{C} / \mathrm{EBP} \alpha$ were identified (Figure 2B).

\section{Overexpression of C/EBP $\alpha$ in K-562 cells stimulates I antigen and IGnTC gene expression}

Overexpression experiments in K-562 cells were performed to study whether the transcription factors Oct-2, Sp1, and C/EBP $\alpha$ affected $I G n T C$ gene expression. Flow cytometry analyses showed that the cell surface I antigen on K-562 cells was slightly increased with overexpression of Oct-2 and $\mathrm{Sp} 1$, whereas it was markedly enhanced by $\mathrm{C} / \mathrm{EBP} \alpha$ overexpression (Figure 3A). Coexpression experiments further demonstrated that Oct-2 and $\mathrm{Sp} 1$ do not act in synergy with $\mathrm{C} / \mathrm{EBP} \alpha$ and have little effect in the induction of I antigen expression (Figure S1).

The expression profiles of the $3 I G n T$ forms show that the transcription of the IGnTC gene, but not IGnTA and IGnTB, was induced dramatically in $\mathrm{K}-562$ cells with $\mathrm{C} / \mathrm{EBP} \alpha$ expression (Figure 3B). This profile of IGnTC gene induction is consistent with that observed in the butyrate-induced erythroid differentiation of the same cell, and indicates that the ability of $\mathrm{C} / \mathrm{EBP} \alpha$ to enhance I antigen formation in K-562 cells is mediated through the capability to stimulate IGnTC gene expression. The luciferase activity in the K-562 cells cotransfected with the $-318 /+62$-bp reporter construct and the $\mathrm{C} / \mathrm{EBP} \alpha$ expression plasmid was much higher than that in analogs transfected with the same reporter vector and the mock pcDNA3.1 plasmid (Figure 3C). This demonstrates the enhancer activity of the IGnTC -318 to $+62-\mathrm{bp}$ region in the presence of $\mathrm{C} / \mathrm{EBP} \alpha$ transcription factor.

These results are clear evidence of the functional role of $\mathrm{C} / \mathrm{EBP} \alpha$ in the stimulation of IGnTC gene expression and subsequent I antigen formation in the erythroid differentiation of K-562 cells.

\section{C/EBP $\alpha$ associates with IGnTC gene promoter after butyrate treatment}

The association of Oct-2, Sp1, and $\mathrm{C} / \mathrm{EBP} \alpha$ transcription factors with the IGnTC $5^{\prime}$ region $(-322$ to $+62 \mathrm{bp})$ in $\mathrm{K}-562$ cells was examined using ChIP analysis. The results reveal that Oct-2 and $\mathrm{Sp} 1$ associated with the IGnTC 5' region; however, there was no definite change in association status comparing the butyrate-treated and untreated cells (Figure 4). By contrast, there appeared to be almost no association between $\mathrm{C} / \mathrm{EBP} \alpha$ and the -322 to $+62-\mathrm{bp}$ region in the untreated K-562 cells; however, there was significant association after butyrate treatment.

\section{Induction of the IGnTC gene is accompanied by C/EBP $\alpha$ dephosphorylation}

The results of the overexpression experiment make evident the determining role of $\mathrm{C} / \mathrm{EBP} \alpha$ in the induction of I antigen formation in $\mathrm{K}-562$ cells, while ChIP analysis shows that the association of $\mathrm{C} / \mathrm{EBP} \alpha$ with the IGnTC 5' promoter region is induced by sodium butyrate treatment. The expressed mRNA and protein levels of $\mathrm{C} / \mathrm{EBP} \alpha$ in butyrate-treated and untreated K-562 cells were subsequently examined further. The quantity of $C / E B P \alpha$ transcript in the butyrate-treated cells increased to about 2.5 -fold that of the untreated cells (Figure 5A); however, there was no noticeable change in the expressed $\mathrm{C} / \mathrm{EBP} \alpha$ protein, observed exclusively in the nuclear fractions but not in the cytoplasmic fractions, comparing the butyrate-treated and untreated cells (Figure 5B). Only the $42-\mathrm{kDa}$ products of $\mathrm{C} / \mathrm{EBP} \alpha$ were observed; the $30-\mathrm{kDa}$ alternativetranslated product ${ }^{33}$ was not detected in our Western blot analysis.

It has been shown that posttranslational modifications of phosphorylation ${ }^{34-37}$ and SUMOylation ${ }^{38}$ may affect $\mathrm{C} / \mathrm{EBP} \alpha$ function. Thus, the phosphorylation and SUMOylation status of $\mathrm{C} / \mathrm{EBP} \alpha$ in K-562 cells was examined. Western blotting with anti-SUMO-1 antibody was used for the detection of the immunoprecipated nuclear $\mathrm{C} / \mathrm{EBP} \alpha$ proteins, and it appeared that SUMO modification did not take place on $\mathrm{C} / \mathrm{EBP} \alpha$ in butyrate-treated/untreated K-562 cells (data not shown). In contrast to SUMOylation, phosphorylation was demonstrated on $\mathrm{C} / \mathrm{EBP} \alpha$ (Figure 5C). Detection with anti-phosphoTyr/Thr/Ser antibody revealed slightly decreased phosphorylation status in the butyrate-treated K-562 cells compared with the untreated cells. The phosphorylated residues were further dissected using anti-phosphoTyr, anti-phosphoThr, and antiphosphoSer antibodies. The results suggest phosphorylation occurrence at Thr and Ser residues, but not Tyr, and that the phosphoThr content remained unchanged, while that of phosphoSer was significantly decreased, after butyrate treatment in K-562 cells. 
A
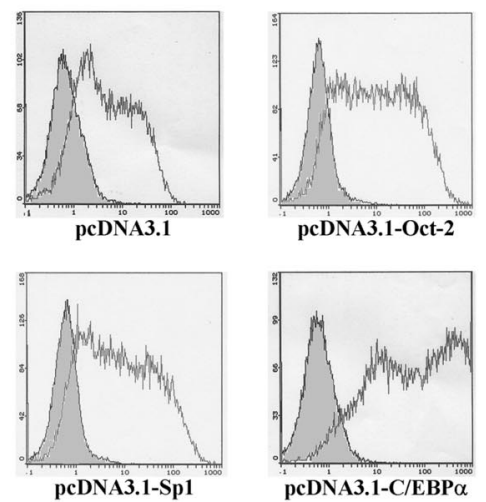

B

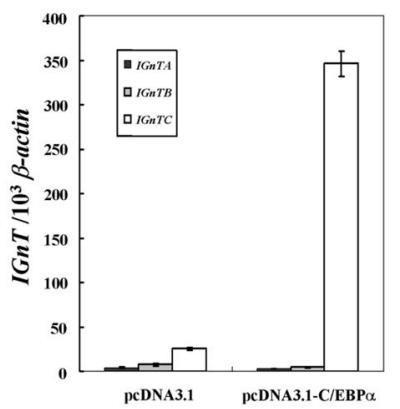

C

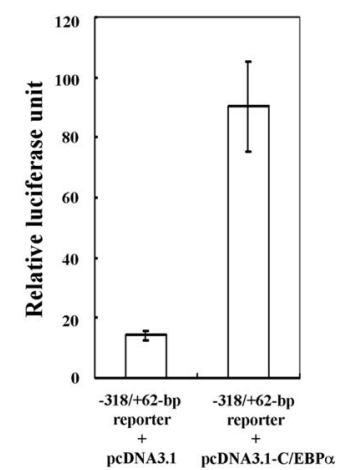

Figure 3. Overexpression of Oct-2, Spl, and C/EBP $\alpha$ in K-562 cells. (A) Expressions of I antigen in the K-562 cells with overexpression of Oct-2, Sp1, and $\mathrm{C} / \mathrm{EBP} \alpha$. The pcDNA3.1 expression vector harboring the respective full coding cDNAs of Oct-2, Sp1, or $C / E B P \alpha$ was transfected into the $\mathrm{K}-562$ cells. $\mathrm{K}-562$ cells were split into 6-well culture plates at a density of $2 \times 10^{5} \mathrm{cells} / \mathrm{mL}$, and transfected with $1.0 \mu \mathrm{g}$ of the constructed and mock pcDNA3.1 expression vector. The antibiotic-selected cells were then analyzed for the expression of I antigen using flow cytometry. Open and shaded areas are representative of the cells detected with anti-I mAb (1:5 dilution) and FITC-conjugated secondary antibody, and with FITC-conjugated secondary antibody only, respectively. (B) Expression profiles for IGnT transcripts in the K-562 cells with C/EBP $\alpha$ overexpression. The expressions of the IGnTA, IGnTB, and IGnTC transcripts in the K-562 cells transfected with the $\mathrm{C} / \mathrm{EBP} \alpha$ expression vector or mock pcDNA3.1 plasmid were analyzed using real-time PCR. Quantities of the IGnT transcripts were normalized to that of $\beta$-actin transcript in each sample. Data were obtained from 3 detections; standard deviations are shown. (C) Transcriptional activity of C/EBP $\alpha$ on IGnTC gene 5' promoter. K-562 cells were cotransfected with the $-318 /+62$-bp reporter construct and the C/EBP $\alpha$ expression vector or with the same reporter vector and mock pcDNA3.1 plasmid. After transfection for 48 hours, the cells were harvested to analyze the activity of the expressed luciferase. Results are presented as averages of luciferase activities from 3 repetitions; standard deviations are shown.

Some elevation of $C / E B P \alpha$ transcript levels was exhibited; however, the protein levels remained unchanged in undifferentiated and erythropoietic-differentiated K-562 cells. Thus, it appears that

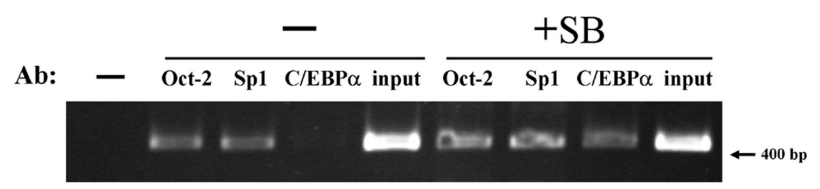

Figure 4. Association of Oct-2, Sp1, and C/EBP $\alpha$ transcription factors with the IGnTC gene $5^{\prime}$ promoter region. The association of Oct-2, Sp1, and C/EBP $\alpha$ transcription factors with the $5^{\prime}$ promoter region ( -322 to $+62 \mathrm{bp}$ ) of the IGnTC gene in K-562 cells was examined using ChIP analysis. A total of $1 \times 10^{7} \mathrm{~K}-562$ cells with or without sodium butyrate treatment (indicated as $+\mathrm{SB}$ and - , respectively) were used. The chromatin DNAs immunoprecipitated with 1:500 dilutions of anti-Oct-2, anti-Sp1, or anti-C/EBP $\alpha$ antibodies $(\mathrm{Ab})$ and the input DNA controls were used for PCR amplification. Butyrate-treated cells were used for the no-antibody control in PCR amplification (leftmost lane).
A

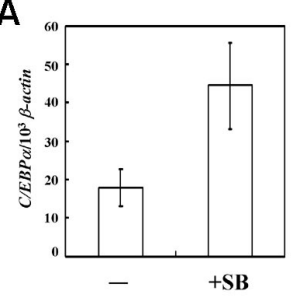

B

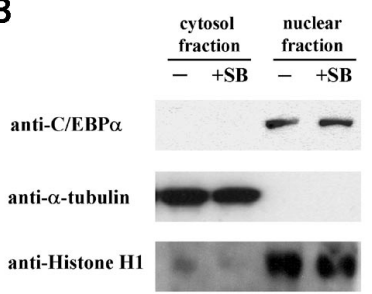

C
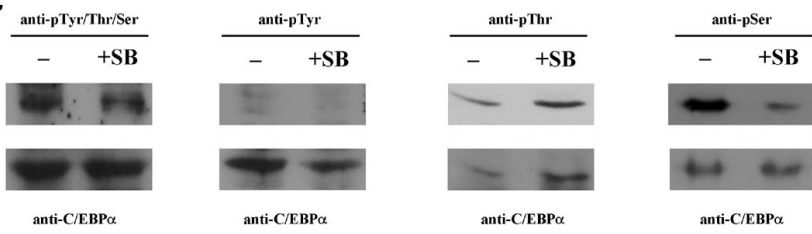

Figure 5. Expression and phosphorylation status of $\mathrm{C} / \mathrm{EBP} \alpha$ in $\mathrm{K}-562$ cells. (A) Expression of $C / E B P \alpha$ transcript. Expressions of $C / E B P \alpha$ transcript in sodium butyrate-treated and untreated K-562 cells (+SB and -, respectively) were compared using real-time PCR. The quantity of the $C / E B P \alpha$ transcript was normalized to that of the $\beta$-actin transcript in each sample. Data were obtained from 3 detections; standard deviations are shown. (B) Western blotting for $\mathrm{C} / \mathrm{EBP} \alpha . \mathrm{C} / \mathrm{EBP} \alpha$ protein levels in the cytoplasmic and nuclear fractions of sodium butyrate-treated and untreated K-562 cells were analyzed using Western blotting with anti-C/EBP $\alpha$ antibody (1:500 dilution). After stripping, the membrane was detected successively with the antibodies against $\alpha$-tubulin (1:5000 dilution) and histone $\mathrm{H} 1$ (1:500 dilution), which are exclusively present in the cytosol and nucleus, respectively. (C) Phosphorylation status of $\mathrm{C} / \mathrm{EBP} \alpha$. Nuclear proteins, prepared from K-562 cells with or without sodium butyrate treatment were immunoprecipitated using anti-C/EBP $\alpha$ antibody. The bound proteins were then analyzed with Western blotting using the following antibodies: anti-phosphoTyr/Thr/Ser (1:4000 dilution), anti-phosphoTyr (1:2000 dilution), anti-phosphoThr (1:1000 dilution), and anti-phosphoSer (1:2000 dilution) (top row of panels). Each blot was then stripped and detected with anti-C/EBP $\alpha$ antibody (bottom row of panels).

the $\mathrm{C} / \mathrm{EBP} \alpha$ binding and induction capabilities for the IGnTC promoter and $I G n T C$ transcription, respectively, are not determined at the transcriptional and translational levels of control, but accompany changes in phosphorylation status. These findings suggest that posttranslational regulation, such as phosphorylation (possibly dephosphorylation of certain Ser residues), may play a crucial role in $\mathrm{C} / \mathrm{EBP} \alpha I G n T C$-activation function.

\section{Expression profiles of I antigen, IGnT gene, and C/EBP $\alpha$, and ChIP analysis in adult and cord $\mathrm{CD} 34^{+}, \mathrm{CD} 71^{+}$, and E-cultured cells}

To elucidate whether $\mathrm{C} / \mathrm{EBP} \alpha$ plays a similar role in in vivo erythropoiesis to that demonstrated using the K-562 cell model, the $\mathrm{CD}_{4}{ }^{+}$and $\mathrm{CD} 71^{+}$blood progenitor cells and E-cultured cells from adults and umbilical cords were subjected to further investigation.

The $\mathrm{CD} 34^{+}$and $\mathrm{CD}_{71^{+}}$cells were isolated as described in "Isolation of $\mathrm{CD}_{3} 4^{+}$and $\mathrm{CD} 71^{+}$cells and E culture." Flow cytometry analyses showed that more than $95 \%$ of the collected cells possessed the respective CD marker (data not shown). Differentiation of the adult and cord CD $34^{+}$cells into erythrocyte lineage was induced in E culture for 7 days, with most $(>99 \%)$ becoming CD71-marker positive and with only a trace of glycophorin A detected on the cell surfaces (data not shown), suggesting cellular differentiation into early erythroblasts. When the cells were cultured for 18 days, the CD71 marker declined, and glycophorin A was noticeably expressed, indicating that the cells had further differentiated into late erythroblasts. The early erythroblasts, differentiated from $\mathrm{CD} 34^{+}$cells in E culture for 7 days, were used in the following analyses. 
A



$\mathrm{CD34}^{+}$cells

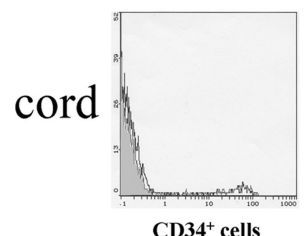

$\mathrm{CD34}^{+}$cells



$\mathrm{CD}^{+} 1^{+}$cells

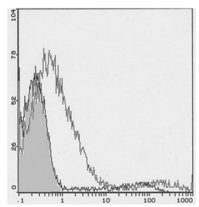

$\mathrm{CD} 1^{+}$cells

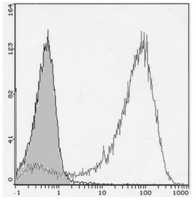

E-cultured cells

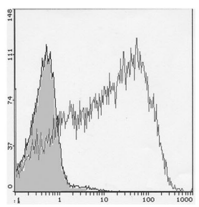

E-cultured cells
C



anti-Histone $\mathrm{H} 1$

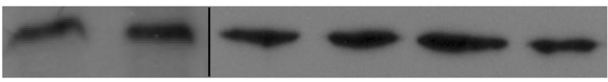

D

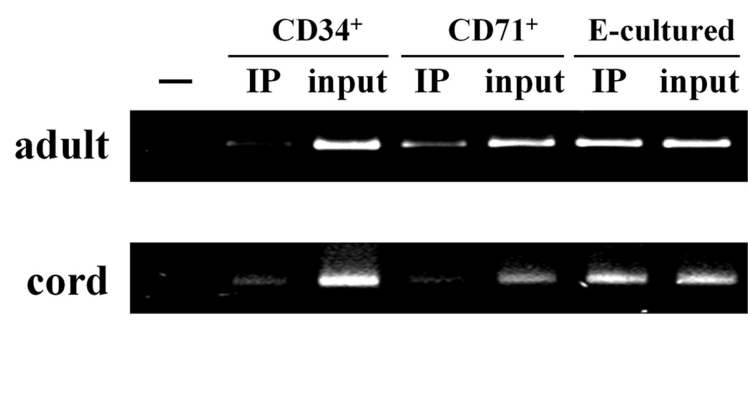

Figure 6. Expression profiles of I antigen, IGnT, and C/EBP $\alpha$, and ChIP analysis in adult and cord CD34+, CD71 ${ }^{+}$, and E-cultured cells. (A) Flow cytometry analysis for I antigen expression. Expressions of the cell-surface I antigens were analyzed using flow cytometry and detected with anti-I mAb (1:5 dilution). Open and shaded areas represent cells detected with anti-I mAb and FITC-conjugated secondary antibody, and with FITC-conjugated secondary antibody only, respectively. (B) Expressions of IGnT and $C / E B P \alpha$ transcripts. Real-time PCR was used to quantify the IGnT and $C / E B P \alpha$ transcripts in the cDNA samples. The quantities of $I G n T$ (left panel) and $C / E B P \alpha$ (right panel) transcripts were normalized to that of the $\beta$-actin transcript. Data were obtained from 3 detections; standard deviations are shown. (C) Western blotting for C/EBP $\alpha$. Nuclear fractions of the adult and cord CD $34^{+}, \mathrm{CD} 71^{+}$, and E-cultured cells were analyzed for the expression of $\mathrm{C} / \mathrm{EBP} \alpha \mathrm{protein}$. After stripping, the membranes were detected with anti-histone $\mathrm{H} 1$ antibody. Vertical lines have been inserted to indicate repositioned gel lanes. (D) ChIP analysis. For ChIP analysis, $2 \times 10^{6}$ adult and $1 \times 10^{6}$ cord cells were used (top and bottom panels, respectively). The chromatin DNAs immunoprecipitated with anti-C/EBP $\alpha$ antibody and input DNA controls were used for PCR amplification (indicated as IP and input, respectively). CD71+ cells were used for the no-antibody controls in PCR amplification (leftmost lanes).

The I antigen was found to weakly express on adult CD34+ cells, and was markedly increased in adult CD71+ cells (Figure 6A). The increase was even more prominent in the E-cultured cells from adults. In the cord cells, I antigen was deficient in the $\mathrm{CD} 34^{+}$cells, with only a trace of I detected on the CD $71^{+}$cells. These results agree with previous findings that fetal and cord red cells contained only modest amounts of the I antigen. ${ }^{9,10}$ When the cord $\mathrm{CD}_{3}{ }^{+}$cells differentiated into early erythroblasts in $\mathrm{E}$ culture, the level of I antigen increased noticeably; however, the amplitude of the increase was less than that for the adult E-cultured cells. Thus, it appears reasonable to suggest that I antigen expression can be induced in cord CD34+ cells using this in vitro E culture system; however, it does not seem to occur in in vivo fetal erythropoiesis, as the cord $\mathrm{CD} 71^{+}$cells do not express sufficient I antigen.

The expression profiles of $I G n T$ transcripts show that the expression of $I G n T C$, but not $I G n T A$ and $I G n T B$, was markedly increased in adult $\mathrm{CD} 71^{+}$cells, and even more so in the adult E-cultured cells, when compared with adult $\mathrm{CD} 34^{+}$cells (Figure $6 \mathrm{~B}$ left). In the cord cells, expression of the IGnTC gene was slightly enhanced in the E-cultured cells, but not in the CD71 ${ }^{+}$ cells. These profiles demonstrate a good correlation between elevation of IGnTC gene expression and increased I antigen formation in these cells, again illustrating that I antigen formation in erythrocyte-lineage cells is determined by the IGnTC gene.

Little variation was observed in the profiles of the $C / E B P \alpha$ transcript among these cells (Figure 6B right), however, except in the adult E-cultured cells, which exhibited notable elevation of $C / E B P \alpha$ expression. Nevertheless, despite the similar levels of the $C / E B P \alpha$ transcript in adult $\mathrm{CD} 34^{+}$and $\mathrm{CD} 71^{+}$cells, $\mathrm{C} / \mathrm{EBP} \alpha$ protein was not detected in adult $\mathrm{CD} 34^{+}$cells although it was clearly present in adult $\mathrm{CD} 71^{+}$cells (Figure 6C). Furthermore, increased $\mathrm{C} / \mathrm{EBP} \alpha$ protein level was not observed in the adult E-cultured cells, their increased transcript levels notwithstanding. It has been shown that translational repression, due to the presence of an upstream open reading frame in the $5^{\prime}$ untranslated region of $C / E B P \alpha$ mRNA, provides 1 avenue for regulating $\mathrm{C} / \mathrm{EBP} \alpha$ expression. ${ }^{39}$ This may explain the absence of $\mathrm{C} / \mathrm{EBP} \alpha$ protein in adult $\mathrm{CD}^{+} 4^{+}$cells; nevertheless, further evidence is required to confirm this assumption. In contrast to the adult $\mathrm{CD} 34^{+}$cells, there is marked expression of $\mathrm{C} / \mathrm{EBP} \alpha$ protein in cord $\mathrm{CD} 34^{+}$cells. The $\mathrm{C} / \mathrm{EBP} \alpha$ protein levels in all 3 types of cord cells were parallel, and were similar to those levels in adult $\mathrm{CD}_{7}{ }^{+}$and E-cultured cells, although the IGnTC and I antigen expressions in these cells of different origins (adult and cord) were quite different.

The results of ChIP analysis (Figure 6D) reveals that the profiles of the association between $\mathrm{C} / \mathrm{EBP} \alpha$ and the IGnTC promoter 
region paralleled the $I G n T C$ induction in these adult and cord cells, and was similar to those demonstrated using the K-562 cell model; that is, notwithstanding that $\mathrm{C} / \mathrm{EBP} \alpha$ protein levels were similar, the association between $\mathrm{C} / \mathrm{EBP} \alpha$ and the IGnTC promoter altered notably and was well correlated with activation of IGnTC expression in the cells. Once again, this suggests that certain posttranslational mechanisms are required for functional activation of the IGnTC gene by $\mathrm{C} / \mathrm{EBP} \alpha$.

The effect of sodium butyrate on $\mathrm{CD} 4^{+}$cells was also explored. However, inductions of I antigen and $I G n T$ gene expressions were not detected in the cord and adult $\mathrm{CD} 34^{+}$cells treated with sodium butyrate (for 5 and 10 days; data not shown). It is believed that K-562 and hemopoietic progenitor CD34+ cells are quite different in terms of cellular status. K-562 are leukemia cells with a definite erythroid character. Thus, sodium butyrate treatment alone in $\mathrm{CD}_{3} 4^{+}$cells may not be adequate to stimulate similar responses to those observed in the K-562 cells.

\section{Overexpression of C/EBP $\alpha$ in $C D 34^{+}$cells stimulates I antigen and IGnTC gene expression}

The $\mathrm{C} / \mathrm{EBP} \alpha$ factor was directly introduced into adult and cord $\mathrm{CD}_{3}{ }^{+}$cells using the lentiviral expression system. Induction of I antigen expression (Figure 7A), significant in adult cells and to a lesser extent in cord cells, and stimulation of IGnTC gene transcription (Figure 7B) was observed in the cells transduced with virions prepared using the pLenti6-C/EBP $\alpha$ gene transfer vector. This result provides direct evidence of the determining role of $\mathrm{C} / \mathrm{EBP} \alpha$ in the stimulation of IGnTC gene expression and I antigen formation.

It has been reported that overexpression of $\mathrm{C} / \mathrm{EBP} \alpha$ in human $\mathrm{CD} 34^{+}$cells leads to granulocytic differentiation. ${ }^{40}$ In our $\mathrm{C} / \mathrm{EBP} \alpha$ overexpression experiments in $\mathrm{CD}_{3} 4^{+}$and $\mathrm{K}-562$ cells, the possibility of differentiation of the transfected cells into granulocytic lineage, as suggested by the results of previous investigations, cannot be excluded; however, overexpression of $\mathrm{C} / \mathrm{EBP} \alpha$ did indeed induce IGnTC and I antigen expression in the transfected cells. In combination with other results observed using the K-562 erythroid differentiation model, this evidence demonstrates the determining role of $\mathrm{C} / \mathrm{EBP} \alpha$ in I antigen formation in erythroid differentiation.

\section{Discussion}

Several explanations for the prevention of severe hemolytic disease in the fetus and newborn (HDFN) due to $\mathrm{ABO}$ incompatibility have been proposed, ${ }^{4}$ with the weak expressions of the $\mathrm{A}$ and $\mathrm{B}$ antigens due to the straight-chain i structure on fetal red cells recognized as 1 of the mechanisms. ${ }^{4,18,19}$ The I antigen on red cells is controlled to appear after birth, suggesting that the formation of I branching structure should have an elaborate biological significance for postnatal red cells. In the present investigation, it was determined that the phenotypic transition from straight-chain i to branchedchain I on red cells is regulated by the transcription factor $\mathrm{C} / \mathrm{EBP} \alpha$, which enhances transcription of the IGnTC gene and consequently leads to the I branching formation.

Despite the presence of $\operatorname{IgG}$ anti-A and anti-B antibodies in the serum of group $\mathrm{O}$ mothers, severe HDFN caused by these antibodies is rare ${ }^{41} \mathrm{An} \mathrm{IgG}$ antibody molecule is able to attach both combining sites to its binding antigen, a condition called monogamous bivalency, ${ }^{42}$ with binding of the antibody to 2 or more
A
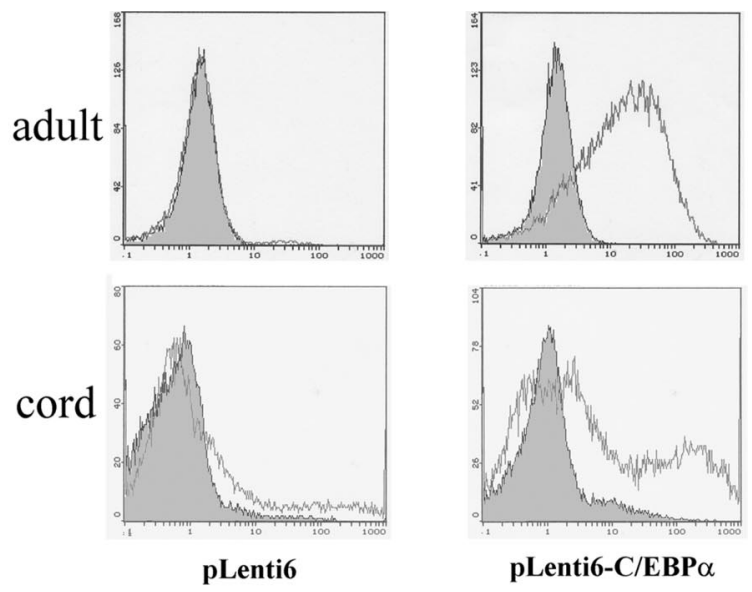

B

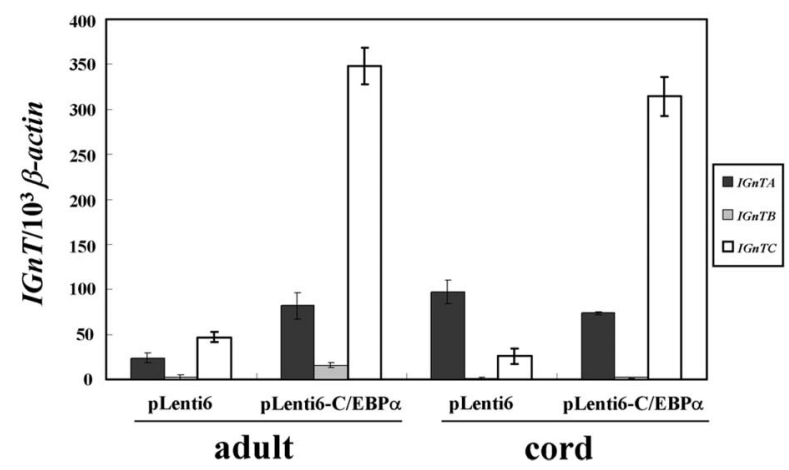

Figure 7. Lentiviral expression of $\mathrm{C} / \mathrm{EBP} \alpha$ in adult and cord $\mathrm{CD} 34^{+}$cells. (A) Flow cytometry analysis for I antigen expression. Expression of the I antigen on the cells transduced with the virions prepared from the pLenti6-C/EBP $\alpha$ gene transfer vector, which harbored full $C / E B P \alpha$ coding $C D N A$, and those transduced with the virions prepared from the mock pLenti6 vector were analyzed using flow cytometry and detected with anti-I mAb (1:10 dilution). Open and shaded areas indicate cells detected with anti-I $\mathrm{mAb}$ and FITC-conjugated secondary antibody, and with FITC-conjugated secondary antibody only, respectively. (B) Expression profiles of IGnT transcripts. Real-time PCR was used to quantify the IGnT and $\beta$-actin transcripts. Quantities of the IGnTA, IGnTB, and IGnTC transcripts were normalized to that of $\beta$-actin transcript in each sample. Data were obtained from 3 detections; standard deviations are shown.

binding sites favored over analogous single-site attachment by a factor greater than $10^{3}$ or $10^{4} \cdot{ }^{43,44}$ The straight and branched poly-LacNAc structures on red cells can be further modified into the blood group A and B antigens. The paucity and spatial configuration of the $\mathrm{A}$ and $\mathrm{B}$ antigens carried by the straight poly-LacNAc chains restrain the monogamous bivalent binding of IgG anti-A and anti-B antibodies, ${ }^{18}$ and thus the straight polyLacNAc structures on the fetal and neonatal red cells lead to very weak reactivity of the cells with anti-A and anti-B antibodies. ${ }^{41}$ The i-to-I transition in red cells, regulated to take place after birth, occurs at around the same time as the shift from fetal hemoglobin to adult hemoglobin. Furthermore, altered expression patterns for the I and $\mathrm{i}$ antigens have often been observed during oncogenetic processes. ${ }^{19,45}$ Based on these observations, it appears reasonable to infer that the transition between straight and branched polyLacNAc structures should play a significant, but as yet unknown, cellular role.

The uncommon molecular genetic architecture of the $I$ gene locus, which expresses the $3 I G n T$ transcripts under the control of specific regulatory mechanisms, ${ }^{21,22}$ affords the complex regulation of the spatially and temporally specific expression of the I antigen in various cells. For example, the IGnTC gene is induced during the 
erythroid differentiation processes, as presented in this study, whereas when hemopoietic cells differentiate into monocytic lineage, expression of the $I G n T B$ gene is markedly increased and the cell surface I antigen is elevated (Y.-C.T. and L.-C.Y., unpublished data April 2005). The present study has demonstrated the determining role of $\mathrm{C} / \mathrm{EBP} \alpha$ in the i-to-I transition in red cells. $\mathrm{C} / \mathrm{EBP} \alpha$ belongs to a family of leucine-zipper transcription factors. ${ }^{33,46}$ These proteins share related $\mathrm{N}$-terminal transactivation domains, DNA-binding regions, and C-terminal leucine-zipper protein interaction domains. $\mathrm{C} / \mathrm{EBP} \alpha$ binds as a homodimer or heterodimer with other C/EBP members or other transcription factors. Further, critical functions have been demonstrated in terms of regulating the balance between cell proliferation and differentiation, particularly in hepatocytes, adipocytes, and hemopoietic cells. In hemopoietic system, it is well known that $\mathrm{C} / \mathrm{EBP} \alpha$ plays a crucial role in the development of granulocytes and controls granulopoietic differentiation and proliferation in a stage-specific manner. ${ }^{47,48}$ In addition, it has been demonstrated that $\mathrm{C} / \mathrm{EBP} \alpha$ regulates the repopulating activity of hemopoietic stem cells. ${ }^{49}$

With the exception of granulocytic lineage, $\mathrm{C} / \mathrm{EBP} \alpha$ has not been implicated in the differentiation of other hemopoietic lineages. ${ }^{50}$ Thus, the finding that $\mathrm{I}$ antigen formation in erythroid differentiation is determined by $\mathrm{C} / \mathrm{EBP} \alpha$ was somewhat unexpected. However, it is well known that $\mathrm{C} / \mathrm{EBP} \alpha$ is a transcription factor with multiple functions. The variety of $\mathrm{C} / \mathrm{EBP} \alpha$ functions is manipulated in a number of ways, including translational control by alternative use of initiation codons, ${ }^{51}$ interaction with various transcription factors, and phosphorylation-mediated changes in DNA-binding activity, transactivation potential, and nuclear localization. ${ }^{33,46,47}$ Phosphorylation appears to play a critical role in the modulation of $\mathrm{C} / \mathrm{EBP} \alpha$ function. For example, protein kinase $\mathrm{C}$ can phosphorylate $\mathrm{C} / \mathrm{EBP} \alpha$ at Ser residues, leading to an attenuation of its DNA-binding activity. ${ }^{34}$ Further, signaling through the phosphatidylinositol 3-kinase (PI3K)-Akt pathway induces protein phosphatase 2A-mediated dephosphorylation of mouse $\mathrm{C} / \mathrm{EBP} \alpha$ on Ser193 in liver tumor cells, leading to blockage of $\mathrm{C} / \mathrm{EBP} \alpha$-mediated growth inhibition. ${ }^{36}$ Furthermore, it has been proven that phosphorylation of $\mathrm{C} / \mathrm{EBP} \alpha$ on Ser-21, mediated by extracellular signalregulated kinase (ERK) $1 / 2$, inhibits the ability of $\mathrm{C} / \mathrm{EBP} \alpha$ to induce granulopoiesis. ${ }^{35,37}$

The IGTC-activation activity of $\mathrm{C} / \mathrm{EBP} \alpha$ also appears to be modulated at a posttranslational level. Our preliminary results show that dephosphorylation of $\mathrm{C} / \mathrm{EBP} \alpha$ at certain Ser residues is accompanied by the enhancement of DNA binding of $\mathrm{C} / \mathrm{EBP} \alpha$ to its binding motif in the IGnTC promoter region and the induction of $I G n T C$ gene expression. Further dissections are required to detailed elaboration of this posttranslational mechanism of C/EBP $\alpha I G n T C$ activation function. Apart from the phosphorylation modification, it has also been demonstrated that translational repression plays an important role in the modulation of $\mathrm{C} / \mathrm{EBP} \alpha$ function. ${ }^{39,52}$ Thus, in spite of the apparent expression of the $C / E B P \alpha$ transcript, the absence of $\mathrm{C} / \mathrm{EBP} \alpha$ protein in adult $\mathrm{CD} 34^{+}$cells, is both perplexing and intriguing. If $\mathrm{C} / \mathrm{EBP} \alpha$ deficiency in adult $\mathrm{CD} 34^{+}$cells does result from translational repression, elucidation of the mechanism leading to the relief of this constraint of translational repression after differentiation into $\mathrm{CD} 71^{+}$cells would be of interest.

Overall, the cellular mechanisms in the erythrocyte-lineage cells can modify $\mathrm{C} / \mathrm{EBP} \alpha$ into the status (phosphorylation status, or some other undetermined modification) possessing the ability to activate the IGnTC gene, leading to I branching formation. Moreover, these cellular mechanisms in the erythrocyte-lineage cells would differ from those in granulocyte-lineage cells, which modify $\mathrm{C} / \mathrm{EBP} \alpha$ to provide regulation of a different set of genes for granulopoiesis. Further, it appears reasonable to suggest that the cellular mechanisms modifying $\mathrm{C} / \mathrm{EBP} \alpha$ to provide IGnTC activation may not be present in, or integral to, the fetal erythrocytelineage cells, and that these are not regulated to appear until birth. Further detailed elaboration of the $\mathrm{C} / \mathrm{EBP} \alpha$ modification required for its I antigen-activation activity would be of interest, therefore, together with articulation of the mechanism responsible for this modification in erythroid differentiation. Hence, further investigations elucidating the molecular bases for maintenance of the $i$ phenotype on fetal red cells and leading to the i-to-I postnatal transition could be carried out and should yield answers that will be of particular interest and significance.

\section{Acknowledgment}

This work was supported in part by grant NSC 96-2320-B-002-074MY3 from the National Science Council, Taiwan.

\section{Authorship}

Contribution: Y.-C.T. designed and performed research, and analyzed data. C.-P.C. contributed vital reagents. C.-Y.H. performed research. C.-H.T. contributed vital reagents. C.-F.S. contributed vital reagents. S.-H.W. performed research. M.-S.C. contributed vital analytical tools. L.-C.Y. designed research, analyzed data, and wrote the paper.

Conflict-of-interest disclosure: The authors declare no competing financial interests.

Correspondence: Lung-Chih Yu, Institute of Biochemical Sciences, National Taiwan University, PO Box 23-106, Taipei 106, Taiwan; e-mail: yulc@ntu.edu.tw.

\section{References}

1. Niemann H, Watanabe K, Hakomori S, Childs RA, Feizi T. Blood group i and I activities of "lacto$\mathrm{N}$-norhexaosylceramide" and its analogues: the structural requirements for i-specificity. Biochem Biophys Res Commun. 1978;81:1286-1293.

2. Watanabe K, Hakomori S, Childs RA, Feizi T. Characterization of a blood group I-active ganglioside. J Biol Chem. 1979;254:3221-3228.

3. Koscielak J, Zdebska E, Wilczynska Z, MillerPodraza H, Dzierzkowa-Borodej W. Immunochemistry of li-activity glycosphingolipids. Eur J Biochem. 1979;96:331-337.

4. Issitt PD, Anstee DJ. Applied Blood Group Serology. Durham, NC: Montgomery Scientific Publications; 1998.
5. Daniels G. Human Blood Groups. Oxford, England: Blackwell Science; 2002.

6. Wiener AS, Unger LJ, Cohen L, Feldman J. Typespecific cold auto-antibodies as a cause of acquired hemolytic anemia and hemolytic transfusion reactions: biological test with bovine red cells. Ann Intern Med. 1956;44:221-240.

7. Jenkins WJ, Marsh WL, Noades J, Tippett $P$, Sanger R, Race RR. The I antigen and antibody. Vox Sang. 1960;5:97-106.

8. Tippett P, Noades J, Sanger R, et al. Further studies of the I antigen and antibody. Vox Sang. 1960;5:107-121.

9. Marsh WL, Jenkins WJ. Anti-i: a new cold antibody. Nature (London). 1960;188:753.
10. Marsh WL. Anti-i: a cold antibody defining the li relationship in human red cells. $\mathrm{Br} \mathrm{J}$ Haematol. 1961;7:200-209.

11. Marsh WL, Nichols ME, Allen FH. Inhibition of anti-I sera by human milk. Vox Sang. 1970;18: 149-154.

12. Rouger P, Juszczak G, Doinel C, Salmon C. Relationship between I and $\mathrm{H}$ antigens, I: a study of the plasma and saliva of a normal population. Transfusion. 1980;20:536-539.

13. Reid ME, Lomas-Francis C. The Blood Group Antigen FactsBook. San Diego, CA: Academic Press; 1997.

14. Fukuda M, Fukuda M, Hakomori S. Developmental change and genetic defect in the carbohydrate 
structure of band 3 glycoprotein of human erythrocyte membrane. J Biol Chem. 1979;254:37003703.

15. Piller F, Cartron J-P. Biosynthesis of blood group I antigens. J Biol Chem. 1984;259:13385-13390.

16. Marsh WL, Nichols ME, Reid ME. The definition of two I antigen components. Vox Sang. 1971;20: 209-217.

17. Giblett ER, Crookston MC. Agglutinability of red cells by anti-i in patients with Thalassaemia major and other haematological disorders. Nature. 1964;201:1138-1139.

18. Romans DG, Tilley CA, Dorrington KJ. Monogamous bivalency of IgG antibodies, I: deficiency of branched $\mathrm{ABH}$-active oligosaccharide chains on red cells of infants causes the weak antiglobulin reactions in Hemolytic disease of the newborn due to ABO incompatibitity. J Immunol. 1980;124: 2807-2811.

19. Hakomori S-I. Traveling for the glycosphingolipid path. Glycoconj J. 2000;17:627-647.

20. Bierhuizen MFA, Mattei M-G, Fukuda M. Expression of the developmental I antigen by a cloned human cDNA encoding a member of a $\beta-1,6-N$ acetylglucosaminyltransferase gene family. Genes Dev. 1993;7:468-478.

21. Yu L-C, Twu Y-C, Chou M-L, et al. The molecular genetics of the human / locus and molecular background explain the partial association of the adult i phenotype with congenital cataracts. Blood. 2003;101:2081-2088.

22. Inaba N, Hiruma T, Togayachi A, et al. A novel I-branching $\beta$-1,6- $N$-acetylglucosaminyltransferase involved in human blood group I antigen expression. Blood. 2003;101:2870-2876.

23. Yu L-C, Twu Y-C, Chang C-Y, Lin M. Molecular basis of the adult i phenotype and the gene responsible for the expression of the human blood group I antigen. Blood. 2001;98:3840-3845.

24. Twu Y-C, Hsieh C-Y, Yu L-C. Expression of the histo-blood group $B$ gene predominates in $A B$ genotype cells. Transfusion. 2006;46:1988-1996.

25. Ausubel FM, Brent R, Kingston, RE, et al. Current Protocols in Molecular Biology. Hoboken, NJ: John Wiley \& Sons; 1998.

26. Andersson LC, Jokinen M, Gahmberg CG. Induction of erythroid differentiation in the human leukemia cell line K562. Nature. 1979;278:364-365.

27. Hoffman R, Murnane MJ, Benz EJ Jr, et al. Induction of erythropoietic colonies in a human chronic myelogenous leukemia cell line. Blood. 1979;54: 1182-1187.
28. McCaffrey PG, Newsome DA, Fibach E, Yoshida $\mathrm{M}$, Su MS. Induction of $\gamma$-globin by histone deacetylase inhibitors. Blood. 1997;90:20752083.

29. Witt O, Sand K, Pekrun A. Butyrate-induced erythroid differentiation of human K562 leukemia cells involves inhibition of ERK and activation of p38 MAP kinase pathways. Blood. 2000;95:23912396.

30. Testa U, Henri A, Bettaieb A, et al. Regulation of $\mathrm{i}$ and I-antigen expression in the K562 cell line. Cancer Res. 1982;42:4694-4700.

31. Orkin SH, Harosi FI, Leder P. Differentiation in erythroleukemic cells and their somatic hybrids. Proc Nat Acad Sci U S A. 1975;72:98-102.

32. Schug J, Overton GC. TESS: Transcription Element Search Software on the WWW, Technical Report CBIL-TR-1997-1001-v0.0. Available at: http://www.cbil.upenn.edu/tess. Computational Biology and Informatics Laboratory, School of Medicine, University of Pennsylvania; 1997.

33. Ramji DP, Foka P. CCAAT/enhancer-binding proteins: structure, function and regulation. Biochem J. 2002;365:561-575.

34. Mahoney CW, Shuman J, McKnight SL, Chen $\mathrm{H}-\mathrm{C}$, Huang K-P. Phosphorylation of CCAAT-enhancer binding protein by protein kinase $\mathrm{C}$ attenuates site-selective DNA binding. J Biol Chem 1992;267:19396-19403.

35. Ross SE, Radomska HS, Wu B, et al. Phosphorylation of $\mathrm{C} / \mathrm{EBP} \alpha$ inhibits granulopoiesis. Mol Cell Biol. 2004;24:675-686.

36. Wang G-L, lakova P, Wilde M, Awad S, Timchenko NA. Liver tumors escape negative control of proliferation via PI3K/Akt-mediated block of $\mathrm{C} / \mathrm{EBP} \alpha$ growth inhibitory activity. Genes Dev. 2004;18:912-925.

37. Radomska HS, Basseres DS, Zheng R, et al. Block of $\mathrm{C} / \mathrm{EBP} \alpha$ function by phosphorylation in acute myeloid leukemia with FLT3 activating mutations. J Environ Monit. 2006;203:371-381.

38. Subramanian L, Benson MD, Iniguez-Lluhi JA. A synergy control motif within the attenuator domain of CCAAT/enhancer-binding protein $\alpha$ inhibits transcriptional synergy through its PIASy-enhanced modification by SUMO-1 or SUMO-3 J Biol Chem. 2003;278:9134-9141.

39. Lincoln AJ, Monczak Y, Williams SC, Johnson PF. Inhibition of CCAAT/enhancer-binding protein $\alpha$ and $\beta$ translation by upstream open reading frames. J Biol Chem. 1998;273:9552-9560.

40. Cammenga J, Mulloy JC, Berguido FJ, MacGro- gan D, Viale A, Nimer SD. Induction of C/EBP $\alpha$ activity alters gene expression and differentiation of human CD34+ cells. Blood. 2003;101:22062214

41. Rosenfield RE. A-B hemolytic disease of the newborn: analysis of 1480 cord blood specimens, with special reference to the direct antiglobulin test and to the group O mother. Blood. 1955;10: 17-28.

42. Klinman NR, Karush F. Equine anti-hapten antibody, V: the non-precipitability of bivalent antibody. Immunochemistry. 1967;4:387-405.

43. Hornick CL, Karush F. Antibody affinity, III: the role of multivalence. Immunochemistry. 1972;9: 325-340.

44. Gopalakrishnan PV, Karush F. Antibody affinity, VII: multivalent interaction of anti-lactoside antibody. J Immunol. 1974;113:769-778.

45. Hakomori S, Kannagi R. Glycosphingolipids as tumor-associated and differentiation markers. J Natl Cancer I. 1983;71:231-251.

46. Johnson PF. Molecular stop signs: regulation of cell-cycle arrest by C/EBP transcription factors. J Cell Sci. 2005;118:2545-2555.

47. Tenen DG, Hromas R, Licht JD, Zhang D-E. Transcription factors, normal myeloid development, and leukemia. Blood. 1997;90:489-519.

48. Mueller BU, Pabst T. C/EBP $\alpha$ and the pathophysiology of acute myeloid leukemia. Curr Opin Hematol. 2006;13:7-14.

49. Zhang P, Iwasaki-Arai J, Iwasaki H, et al. Enhancement of hematopoietic stem cell repopulating capacity and self-renewal in the absence of the transcription factor $\mathrm{C} / \mathrm{EBP} \alpha$. Immunity. 2004; 21:853-863.

50. Zhang D-E, Zhang P, Wang N-D, Hetherington CJ, Darlington GJ, Tenen DG. Absence of granulocyte colony-stimulating factor signaling and neutrophil development in CCAAT enhancer binding protein $\alpha$-deficient mice. Proc Natl Acad Sci U S A. 1997;94:569-574.

51. An MR, Hsieh C-C, Reisner PD, et al. Evidence for posttranscriptional regulation of $\mathrm{C} / \mathrm{EBP} \alpha$ and $\mathrm{C} / \mathrm{EBP} \beta$ isoform expression during the lipopolysaccharide-mediated acute-phase response. Mol Cell Biol. 1996;16:2295-2306.

52. Perrotti D, Cesi V, Trotta R, et al. BCR-ABL suppresses $\mathrm{C} / \mathrm{EBP} \alpha$ expression through inhibitory action of hnRNP E2. Nat Genet. 2002;30:48-58. 